Tropical Journal of Pharmaceutical Research March 2021; 20 (3): 525-530

ISSN: $1596-5996$ (print); 1596-9827 (electronic)

(C) Pharmacotherapy Group, Faculty of Pharmacy, University of Benin, Benin City, 300001 Nigeria.

\title{
Interleukin-34 protects against sepsis in mice by regulating CXCL1/CCL2 immune response
}

\author{
Jianjun Wang ${ }^{1}$, Feng Yang ${ }^{2}$, Yuanyuan Bu${ }^{1}$, Jinghong Jia ${ }^{1}$, Aibin Cheng ${ }^{1}$, Jihua \\ Zhao $^{4 *}$ \\ ${ }^{1}$ Department of Intensive Medicine, ${ }^{2}$ Department of Neurosurgery, ${ }^{3}$ Department of Anesthesiology, North China University of \\ Science and Technology Affiliated Hospital, ${ }^{4}$ North China University of Science and Technology School of Clinical Medicine, \\ Tangshan City, China
}

*For correspondence: Email: bgfr37@163.com

Sent for review: 19 December 2020

Revised accepted: 6 March 2021

\begin{abstract}
Purpose: To study the protective effect of interleukin-34 (IL-34) against sepsis in mice, and the mechanism involved.

Methods: Ninety healthy male mice were selected and assigned to sham, model and recombinant IL-34 protein groups. The activities of alanine aminotransferase (ALT), aspartate aminotransferase (AST) and lactate dehydrogenase (LDH) were assayed. Moreover, histopathological changes in lung, liver and kidney were recorded, and levels of C-X-C Motif Chemokine Ligand 1 (CXCL1) and C-C Motif Chemokine Ligand 2 (CCL2) in each group of mice were measured.

Results: Peritoneal lavage fluid and serum concentrations of AST, ALT, LDH, CXCL1 and CCL2 were significantly elevated, relative to sham mice $(p<0.05)$. Mice survival in the drug group was markedly increased from day 1 to day 5; also, serum ALT, LDH and AST were significantly reduced, while CXCL1 and CCL2 concentrations in serum and peritoneal lavage fluid were increased, relative to model mice ( $p$ $<0.05)$.

Conclusion: IL-34 improves survival of septic mice by inducing CXCL1/CCL2 immune response, resulting in a protective effect on the airway. Thus, the CXCL1/CCL2 pathway mediated by IL-34 may be useful in the development of drugs for the treatment of sepsis.
\end{abstract}

Keywords: Interleukin-34, Sepsis, CXCL1/CCL2, Protective effect

\begin{abstract}
This is an Open Access article that uses a fund-ing model which does not charge readers or their institutions for access and distributed under the terms of the Creative Commons Attribution License (http://creativecommons.org/licenses/by/4.0) and the Budapest Open Access Initiative (http://www.budapestopenaccessinitiative.org/read), which permit unrestricted use, distribution, and reproduction in any medium, provided the original work is properly credited.
\end{abstract}

Tropical Journal of Pharmaceutical Research is indexed by Science Citation Index (SciSearch), Scopus, International Pharmaceutical Abstract, Chemical Abstracts, Embase, Index Copernicus, EBSCO, African Index Medicus, JournalSeek, Journal Citation Reports/Science Edition, Directory of Open Access Journals (DOAJ), African Journal Online, Bioline International, Open-J-Gate and Pharmacy Abstracts

\section{INTRODUCTION}

Sepsis, an infection caused by bacteria or fungi is a critical and severe disease in clinics. Bacterial infection is the most common cause of sepsis. Relevant statistics have revealed that sepsis is an important cause of death in developed countries, accounting for about $40 \%$ of all mortalities [1]. With advances in medical science and technology, important progress has been made in the treatment of sepsis. However, the incidence of sepsis is still on the increase, thereby impacting negatively on the lives of patients. The pathogenesis of sepsis is not yet fully understood, although it is believed that it may be significantly related to pathogen 
infection, inflammatory pathway activation, and immune dysfunction [2].

Infection activates interleukins and TNF- $\alpha$ to form a complex network with mutual restriction, resulting in generalized damage to organs and tissues. Cytokines play an important role in immunity against infections [3]. Interleukin-34 (IL34 ) is an inflammatory cytokine. In general, IL-34 content is low in vivo. It maintains the survival, development and activation of macrophages and dendritic cells, and promotes the development of epidermal Langerhans cells and microglia cells in the brain. In addition, IL-34 induces the secretion of interleukin-6 (IL-6) and CCL2 in whole blood cells $[4,5]$. Studies have found that IL-34 is involved in rheumatoid arthritis, inflammatory bowel disease and other inflammatory and autoimmune diseases [6]. However, its involvement in sepsis is still unclear. In this study, the effect of IL-34 on sepsis was studied in a C57BL/6 mouse model, and the associated mechanism was investigated.

\section{EXPERIMENTAL}

\section{Animals}

Ninety healthy male C57BL/6 mice (mean weight $=20 \pm 2 \mathrm{~g}$ ) were obtained from Guangdong Yaokang Biotechnology Co. Ltd. \{production license = SCXK (Guangdong) 2020-0054; usage license = SYXK (Guangdong) 2020-0238\}. The mice were fed adaptively for 1 week at laboratory temperature of $22 \pm 3{ }^{\circ} \mathrm{C}$, humidity of $53 \pm 11 \%$, and $12 \mathrm{~h}$ light-12 $\mathrm{h}$ dark cycle.

\section{Main instruments and reagents}

The instruments and reagents used, and their suppliers (in parenthesis) were: real-time fluorescence quantitative PCR instrument (Xi'an Tianlong Technology Co. Ltd., model: Gentier 96E); $-80{ }^{\circ} \mathrm{C}$ ultra-low temperature refrigerator (Beijing Alice Biotechnology Co. Ltd., model: DW-86L626); biological microscope (Shanghai Yuguang Instrument Co. Ltd, Model: WMS1033); constant temperature water bath box (Tianjin Hengao Technology Development Co. Ltd, model HWT-6B); cryogenic high speed centrifuge (Shandong Boke Scientific instrument Co. Ltd, model: TGL-21R); fetal bovine serum (Shanghai Jianglin Biotechnology Co. Ltd); Wright's stain (Shanghai Hengyuan Biotechnology Co. Ltd); recombinant (rec) human IL-34 protein (Abcam Shanghai Trading Co. Ltd); mouse anti-human CXCL1 monoclonal antibody (Shanghai Qunji Biotechnology Co. Ltd), and mouse anti-human CCL2 monoclonal antibody (Shanghai Zhenzheng Biotechnology Co. Ltd).

\section{Animal grouping and treatment}

The animals were assigned to sham, model and rec human IL-34 protein (drug) groups, with 30 mice in each group. Septic mouse model was then established. The mice were anesthetized and their abdominal regions were fixed upward on an operating table. The skin of the abdomen of each mouse was cleaned and disinfected, and a $1.7 \mathrm{~cm}$ longitudinal cut was made in the middle of the abdomen to locate the cecum. The cecum root was subjected to ligation, and the distal end of the cecum ligation site was punctured 2 times. After the removal of the needle, a little stool was extruded from the puncture hole and smeared onto the surface of the ligated cecum. Then, the cecum was put back into the abdominal cavity and sutured layer by layer. Mice in sham group were subjected to laparotomy, but were not ligated. Mice in the drug group were subcutaneously injected with recombinant human IL-34 protein at a dose of $400 \mu \mathrm{g} / \mathrm{kg}$ once a day, 3 days before, and 7 days after surgery.

\section{Assay of IL-34, ALT, AST and LDH}

Mice heart blood samples and peritoneal lavage fluids were collected. For peritoneal lavage, the abdominal cavities of mice were injected with 3 $\mathrm{mL}$ phosphate buffer, and the recovery was over $90 \%$. This was repeated three times and the resultant fluid was placed on ice. Lung tissue samples were taken $24 \mathrm{~h}$ after establishing the mouse model of sepsis. The supernatant was taken after centrifugation and the IL-34 level was determined using enzyme-linked immunosorbent assay. Samples were taken and incubated in a shaker for $120 \mathrm{~min}$. Biotin-labeled antibody was diluted with assay diluent and incubated at room temperature for $60 \mathrm{~min}$. Avidin-labeled horseradish peroxidase was added and incubated for $30 \mathrm{~min}$, followed by addition of enzyme substrate to terminate the reaction. Levels of IL-34 in serum, peritoneal lavage fluids and lung tissue were compared between the sham operation group and the model group. Survival of all groups of mice within 7 days was compared. After $24 \mathrm{~h}$ of establishing the mouse model, $3 \mathrm{~mL}$ of tail venous blood was collected, centrifuged, and supernatant was used for assay of levels of ALT, AST and LDH in each group of mice using automatic biochemical analyzer.

\section{Histological examination of tissues}

Fifteen mice were sacrificed from each group 24 $\mathrm{h}$ after establishing the sepsis model, and the lung, liver and kidney tissues were excised, fixed in formalin solution and embedded in wax. Then, 4- $\mu \mathrm{m}$ paraffin sections were sectioned routinely 
using a microtome. The sections were dewaxed with xylene, dehydrated with anhydrous ethanol, and washed thrice with phosphate buffer, 3 min each time. Then, the sections were stained with eosin and rinsed thrice with phosphate buffer (3 min per wash). The sections were air-dried naturally, dehydrated, made transparent, sealed with neutral gum and observed under a light microscope.

The mouse macrophages were knocked out, and the levels of CXCL1 and CCL2 in each group of mice were measured using enzyme linked immunosorbent assay.

\section{Statistical analysis}

Data are expressed as mean \pm standard deviation (SD). Comparison of IL-34, AST, ALT, LDH, CXCL1 and CCL2 levels, and other measurement data between two groups were carried out with $t$-test, while mean values of single factor and multiple samples were used for comparison among multiple groups. All statistical analyses were done with SPSS 19.0 software. At values of $p<0.05$, differences were considered statistically significant.

\section{RESULTS}

\section{Levels of IL-34 in serum, peritoneal lavage fluid and lung tissue}

The concentrations of IL-34 in serum, peritoneal lavage fluids and lung tissue in the model group were significantly increased, relative to sham mice $(p<0.01)$. These results are presented in Table 1.

\section{Survival rate}

With time, the percentage survival of mice in each group decreased gradually. The \% survival of model mice was markedly reduced from day 1 to day 4 , relative to sham mice. In contrast, the $\%$ survival of mice in drug-treated mice was markedly raised from day 1 to day $5(p<0.05)$. These data are presented in Table 2.

\section{Changes in LDH, AST and ALT activities}

The serum activities of these enzymes were markedly raised in sepsis mice, relative to sham mice. However, they were markedly decreased in the drug group (Table 3).

Table 1: Levels of IL-34 in serum, peritoneal lavage fluid and lung tissue (mean $\pm S D, n=30$ )

\begin{tabular}{lccc}
\hline Group & Serum $(\mathbf{p g} / \mathbf{m L})$ & $\begin{array}{c}\text { Peritoneal lavage fluids } \\
(\mathbf{p g} / \mathbf{m L})\end{array}$ & Lung tissue $(\mathbf{p g} / \mathbf{m L})$ \\
\hline Sham & $5.21 \pm 0.12$ & $15.49 \pm 5.37$ & $416.84 \pm 53.47$ \\
Model & $42.68 \pm 8.53$ & $79.67 \pm 12.59$ & $1012.83 \pm 73.39$ \\
$T$ & 24.115 & 25.683 & 35.950 \\
$P$-value & $<0.001$ & $<0.001$ & $<0.001$ \\
\hline
\end{tabular}

Table 2: Survival rate of the mice

\begin{tabular}{lccccccc}
\hline \multirow{2}{*}{ Group } & Day 1 & Day 2 & Day 3 & Day 4 & Day 5 & Day 6 & Day 7 \\
\hline Sham & $100.00 \pm 0.01$ & $100.00 \pm 0.01$ & $100.00 \pm 0.01$ & $100.00 \pm 0.01$ & $100.00 \pm 0.01$ & $100.00 \pm 0.01$ & $100.00 \pm 0.01$ \\
Model & $86.35 \pm 1.23^{\mathrm{a}}$ & $64.45 \pm 1.48^{\mathrm{a}}$ & $48.68 \pm 2.47^{\mathrm{a}}$ & $39.55 \pm 1.68^{\mathrm{a}}$ & $39.55 \pm 1.68^{\mathrm{a}}$ & $39.55 \pm 1.68^{\mathrm{a}}$ & $39.55 \pm 1.68^{\mathrm{a}}$ \\
Drug & $100.00 \pm 0.01^{\mathrm{b}}$ & $93.65 \pm 1.58^{\mathrm{ab}}$ & $80.11 \pm 2.03^{\mathrm{ab}}$ & $72.33 \pm 3.26^{\mathrm{ab}}$ & $61.25 \pm 2.22^{\mathrm{ab}}$ & $61.25 \pm 2.22^{\mathrm{ab}}$ & $61.25 \pm 2.22^{\mathrm{ab}}$ \\
$F$ & 3694.19 & 6902.53 & 5894.99 & 6127.49 & 10889.04 & 10889.04 & 10889.04 \\
$P$ & $<0.001$ & $<0.001$ & $<0.001$ & $<0.001$ & $<0.001$ & $<0.001$ & $<0.001$ \\
\hline
\end{tabular}

Table 3: Serum AST, ALT and LDH levels of the mice

\begin{tabular}{|c|c|c|c|}
\hline Group & AST $(\mathrm{U} / \mathrm{mL})$ & ALT $(\mathrm{U} / \mathrm{mL})$ & LDH (U/L) \\
\hline Sham & $142.73 \pm 16.42$ & $84.69 \pm 9.58$ & $745.83 \pm 97.82$ \\
\hline Model & $358.94 \pm 63.66^{a}$ & $416.74 \pm 25.84^{a}$ & $1285.66 \pm 116.84^{a}$ \\
\hline Drug & $299.71 \pm 41.11^{a b}$ & $151.69 \pm 49.64^{\mathrm{ab}}$ & $946.83 \pm 101.79^{a b}$ \\
\hline$F$ & 186.86 & 860.83 & 199.49 \\
\hline$P$-value & $<0.001$ & $<0.001$ & $<0.001$ \\
\hline
\end{tabular}


Histopathological changes in liver, lung and kidney of mice

The morphologies of liver, lung and kidney in the sham operation group were normal; the cells were arranged neatly without edema, degeneration or necrosis. In contrast, in the model group, the liver cells were in disorderly pattern, with large spaces between cells. Moreover, liver tissue congestion and local lung tissue congestion points were seen. Inflammatory cell infiltration occurred in the lung interstitium and alveolar cavity. Vacuolar degeneration occurred in the renal tubular epithelial cells of nephridial tissue, and a large number of inflammatory cells infiltrated the lumen. In contrast, the liver, kidney and lung tissues of mice in the drug group were significantly improved, relative to the model group. These results are shown in Figure 1.

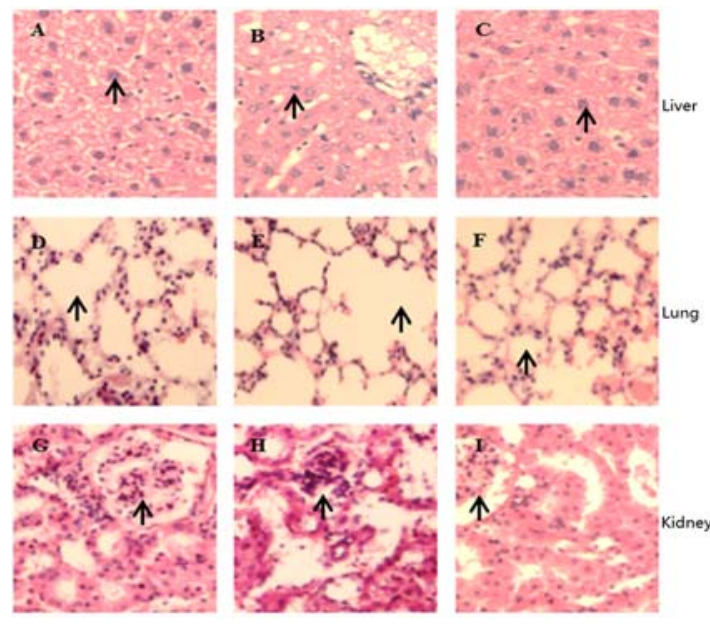

Figure 1: Photomicrographs of liver, lung and kidney sections in the various mice groups. A, D \& G: sham operation group; B, E \& H: model group; C, F \& I: drug group

CXCL1 and CCL2 levels in serum and peritoneal lavage fluid

The levels of CXCL1 and CCL2 in serum and peritoneal lavage fluids of mice in sepsis mice and drug group were markedly raised, relative to the corresponding levels in sham operation mice $(p<0.05)$. These results are presented in Table 4 .

\section{DISCUSSION}

Sepsis is a systemic inflammatory reaction characterized by high morbidity and mortality. According to statistics, the mortality of patients with sepsis may be as high as $60 \%$, which makes it a significant cause of death for patients in intensive care units. Studies have found that infection may cause a series of adverse reactions that may lead to tissue and organ damage, thereby seriously affecting the life of patients [7]. The pathogenesis of sepsis is still unclear. However, studies have shown that sepsis, which involves a variety of cytokines, leads to impairment of immune balance, and increases chances of secondary infection, thereby making the treatment of sepsis more difficult [8]. Therefore, it is important to investigate the pathogenesis of sepsis so as to identify likely therapeutic targets for the disease.

It is known that IL-34 is a new homodimer secretory protein belonging to the interleukinfamily. Research has shown that IL-34 upregulates cytokines such as IL- 6 and TNF- $\alpha$, promotes the survival of peripheral blood mononuclear cells, and enhances the production of macrophage colony stimulating factor. In addition, IL-34 reduces neuronal death and glial cell proliferation, thereby exerting obvious neuroprotective effect $[9,10]$.

Some scholars have reported that IL-34 level is significantly increased in rheumatoid arthritis, Sjogren syndrome, inflammatory bowel disease and acute kidney injury [11]. In this study, it was found that the expression of IL-34 in septic mice was significantly increased, suggesting that IL-34 may be important in sepsis. The purpose of this research was to investigate the effect IL-34 on septic mice, and the mechanism involved in the process.

Table 4: Levels of CXCL1 and CCL2 in serum and peritoneal lavage fluid of mice (mean $\pm S D, n=30$ )

\begin{tabular}{lcccc}
\hline \multirow{2}{*}{ Group } & \multicolumn{2}{c}{ Serum $(\mathbf{p g} / \mathbf{m L})$} & \multicolumn{2}{c}{ Peritoneal lavage fluids $(\mathbf{p g} / \mathbf{m L})$} \\
\cline { 2 - 5 } & $\mathbf{C X C L 1}$ & $\mathbf{C C L 2}$ & $\mathbf{C X C L 1}$ & \multicolumn{1}{c}{ C 22} \\
\hline Sham & $21.69 \pm 1.58$ & $96.88 \pm 11.56$ & $20.14 \pm 1.25$ & $125.66 \pm 11.28$ \\
Model & $121.43 \pm 11.42^{\mathrm{a}}$ & $943.52 \pm 148.69^{\mathrm{a}}$ & $151.66 \pm 23.47^{\mathrm{a}}$ & $1026.46 \pm 138.91^{\mathrm{a}}$ \\
Drug & $216.84 \pm 13.55^{\mathrm{ab}}$ & $2347.35 \pm 279.57^{\mathrm{ab}}$ & $274.69 \pm 12.17^{\mathrm{ab}}$ & $2168.52 \pm 175.82^{\mathrm{ab}}$ \\
$F$ & 1353.84 & 579.18 & 1040.98 & 937.06 \\
$P$-value & $<0.001$ & $<0.001$ & $<0.001$ & $<0.001$ \\
\hline
\end{tabular}

a $P<0.05$, vs sham; ${ }^{b} p<0.05$, vs model 
It has been reported that lung injury and liver injury are important causes of sepsis-related death [12]. In this study, the percentage survival and the changes in lung, liver, kidney and other tissues of mice in each group were analyzed, and blood activities of AST, ALT and LDH of mice in each group were assayed.

The results showed that the survival of septic mice was significantly reduced, while the lung, liver, kidney and other tissues were significantly necrotic. However, the survival of mice, as well as the histology of lung, liver and kidney tissues were markedly improved after treatment with recombinant human IL-34 protein.

Thus, recombinant human IL-34 protein reversed the sepsis-induced lesions in lung, liver and kidney. This may be due to the fact that sepsis is a systemic inflammatory response. When sepsis occurs, the levels of inflammatory cytokines such as IL-6, IL-1 $\beta$ and TNF- $\alpha$ are significantly increased. Excessive inflammatory cytokines dilate human blood vessels and increase blood vessel permeability, leading to multi-organ failure, shock and even death [13].

Studies indicate that the level of IL-34, a multifunctional cytokine, is significantly increased, in response to upregulations of inflammation-inducing cytokines, thereby maintaining a balance in anti-inflammatory system [14]. Some scholars have found that inflammation is an important factor in the pathogenesis of sepsis [15]. Cytokines are important bioactive molecules released after activation by immune cells, and they regulate immune function, promote blood cell generation, and repair damaged tissues [16].

The results of this study showed that the levels of CXCL1 and CCL2 in serum and peritoneal lavage fluids of septic mice were significantly elevated. Moreover, CXCL1 and CCL2 were markedly increased after injection of recombinant human IL-34 protein. These findings suggest that IL-34 induces the secretion of neutrophil chemokines CXCL1 and CCL2, and improves immune response. However, the specific mechanism involved is still unclear.

\section{CONCLUSION}

This study has shown that IL-34 may improve the survival of septic mice via induction of CXCL1/CCL2 immune response. Thus, it exerts a protective effect on the airways of septic mice and can be developed for the management of sepsis.

\section{DECLARATIONS}

\section{Conflict of interest}

No conflict of interest is associated with this work.

\section{Contribution of authors}

We declare that this work was performed by the authors named in this article and all liabilities pertaining to claims relating to the content of this article will be borne by the authors. Jihua Zhao designed the study, supervised the data collection, and analyzed the data. Jianjun Wang interpreted the data and prepared the manuscript for publication. Feng Yang, Yuanyuan Bu, Jinghong Jia and Aibin Cheng supervised the data collection, analyzed the data and reviewed the draft of the manuscript.

\section{Open Access}

This is an Open Access article that uses a funding model which does not charge readers or their institutions for access and distributed under the terms of the Creative Commons Attribution License (http://creativecommons.org/licenses/by/ 4.0) and the Budapest Open Access Initiative (http://www.budapestopenaccessinitiative.org/rea d), which permit unrestricted use, distribution, and reproduction in any medium, provided the original work is properly credited.

\section{REFERENCES}

1. Jean-Louis V, Steven MO, John CM, Kevin JT. Sepsis definitions: time for change. Lancet 2018; 381 (9868): 774-775.

2. Mitchell ML, Laura EE, Andrew R. The Surviving Sepsis Campaign Bundle: 2018 update. Intensive Care Med 2018; 44(6): 925-928.

3. Suw YL, Yeoung $C K$, Huck JH, Jeongha $K$, Kyung $L$. Rapid Voltammetric Diagnosis of Escherichia coli Contamination in Nontreated Human Blood Plasma of Healthy and Sepsis-infected Patients. IEEE Sens J 2018; 18(6): 2200-2205.

4. Yin Y, Zhang L, Luo H, Song Z, Xia Y, Yan X, Lin X, Cao $J$, Gao $X$. Interleukin-34 Ameliorates Survival and Bacterial Clearance in Polymicrobial Sepsis. Crit Care Med 2018; 46(6): 1.

5. Jacobs MC, Wiersinga WJ. Interleukin-34: A New Player in the Sepsis Arena. Crit Care Med 2018; 46(6): 1032.

6. Abdel-Rehim AS, Mohamed NA, Shakweer MM. Interleukin-34 as a marker for subclinical proliferative lupus nephritis. Lupus 2020; 29(6): 607-616.

7. Qingqing M, Melissa J, Jana LH, Jacob C, Christopher B, David S, Lisa S, Uli C, Grant F, Yaniv K, Yifan Z,

Trop J Pharm Res, March 2021; 20(3): 529 
Ritankar D. Multicentre validation of a sepsis prediction algorithm using only vital sign data in the emergency department, general ward and ICU. Bmj Open 2018; 8(1): e017833.

8. Thorsten B, Sebastian OD, Silke G, Philip S, Thomas B, Thomas S, Mathias WP, Hendrik B, Stefan H, Gernot M, et al. Next-generation sequencing diagnostics of bacteremia in sepsis (Next GeneSiS-Trial): Study protocol of a prospective, observational, noninterventional, multicenter, clinical trial. Med 2018; 97(6): e9868.

9. Tassili AFW, Jacqueline ML, Hanna KDJ, Onno JDB, Joris JTHR, Nicholas PD, Hermann G, Alex FDV, Wiersinga WJ. Therapeutic Administration of a Monoclonal Anti-ll-1 $\beta$ Antibody Protects Against Experimental Melioidosis. Shock 2016; 46(5): 566-574.

10. Shu L, Feng-Xue Z, Xiu-Juan Z, You-Zhong A. The immunoprotective activity of interleukin-33 in mouse model of cecal ligation and puncture-induced sepsis. Immunol Lett 2016; 169(8): 1-7.

11. Mei YC, Xin L, Yi ML, Li PX, Jing L, Hui S. Effects of IL34 on the secretion of RANKL/OPG by fibroblast-like synoviocytes and peripheral blood mononuclear cells in rheumatoid arthritis. Eur Cytokine Netw 2019; 30(2): 6773.

12. Netanel K, Avraham A, Raja EA, Ran E, Ronen B, Barak $R$, Dror M. Apoptotic cell therapy for cytokine storm associated with acute severe sepsis. Cell Death Dis 2020; 11(7): 535.

13. Ji-Sun $H$, Kyung-Hong $K$, Jiwon $P$, Sang-Min $K$, Hyeongjin C, Yunkyoung L, Inn-Oc H. Glucosamine improves survival in a mouse model of sepsis and attenuates sepsis-induced lung injury and inflammation. J Biol Chem 2018; 294(2): 634-638.

14. Di W, Lin S, Pengyang L, Xianqiang N, Jinsheng Z, Qing Z, Yongfen Q, Bin W. Intermedin1-53 Protects Cardiac Fibroblasts by Inhibiting NLRP3 Inflammasome Activation During Sepsis. Inflamm 2018; 41(2): 505-514.

15. Udomsinprasert $W$, Jittikoon J, Honsawek S. Interleukin34 as a promising clinical biomarker and therapeutic target for inflammatory arthritis. Cytokine Growth Factor Rev 2019; 47(15): 612.

16. Yin-Qiu W, Wen-Jun C Yu-Feng G, Jun Y, Gui-Zhou Z. Serum interleukin-34 level can be an indicator of liver fibrosis in patients with chronic hepatitis $B$ virus infection. World J Gastroenterol 2018; 24(12): 13121320. 